\title{
Taxonomía de los documentos del siglo XVI: las Relaciones Geográficas de Indias para un corpus sobre americanismos léxicos
}

\author{
Taxonomy of Sixteenth-Century Documents: \\ Geographical Relations of the Indies for a Corpus on Lexical Americanisms
}

María-Teresa Cáceres-Lorenzo

Universidad de Las Palmas de Gran Canaria. Correo electrónico: mteresa.caceres@ulpgc.es

\begin{abstract}
Este artículo examina las Relaciones Geográficas de Indias (RGI) a través de cuatro criterios clasificatorios usados para otras tradiciones discursivas: textos no fragmentados, con referencias diacrónicas, diatópicas, diafásicas y diastráticas que informan sobre la oralidad. El objetivo final es demostrar, por medio de un estudio de caso, que las RGI pueden usarse como material para un corpus sobre americanismos léxicos, ya que muestran abundancia de ejemplos de su heterogeneidad y difusión desde el siglo XVI. Además, aportan una novedad como texto administrativo y descriptivo redactado de manera colectiva. A través de una metodología cualitativa y cuantitativa se aplican dichos criterios a veinte RGI (1546-1597). El resultado obtenido muestra el cumplimiento parcial de los criterios de clasificación y la posibilidad de diferenciar por áreas lingüísticas el uso de los americanismos. Este trabajo es una contribución al marco teórico en el que se sustenta una posible taxonomía de los textos coloniales.
\end{abstract}

Palabras clave: tradición discursiva, Relaciones Geográficas de Indias, corpus, americanismo léxico

This article examines the Geographical Relations of the Indies (RGI) through four classification criteria used for other discursive traditions: non - fragmented texts, with diachronic, diatopic, diaphasic and diastrática references that inform orality. The final objective is to demonstrate by means of a case study that the RGIs provide a novelty as an administrative and descriptive text drafted collectively, and as material for a corpus on lexical Americanisms, shows an abundance of examples of its heterogeneity and diffusion since the century XVI. Through a qualitative and quantitative methodology, these criteria are applied to twenty RGI (1546-1597). The result obtained shows the partial fulfillment of the criteria of classification, and the possibility of differentiating by linguistic areas the use of Americanisms. This work is a contribution to the theoretical framework in which a possible taxonomy of the colonial texts is based.

Keywords: discursive tradition, Relaciones Geográficas de Indias, corpus, lexical Americanism 


\section{INTRODUCCIÓN}

En la investigación diacrónica, la creación de una taxonomía de los textos americanos escritos en español es necesaria para recuperar y valorar los ejemplos lingüísticos de la incorporación de los americanismos en soporte documental (Hernández 2012). Se consideran como rasgos distintivos del americanismo léxico en el siglo XVI, la heterogeneidad léxica y semántica que se refleja en los lexemas autóctonos de América y sus derivados, así como los vocablos de los españoles con cambio de significado (Rona 1969; Lope Blanch 1994). Este vocabulario diferencial ya en esta primera centuria es consecuencia del contacto lingüístico, la adaptación de la lengua colonizadora a la realidad americana y las preferencias de los hablantes que difunden unos determinados vocablos que consideran propios (Moreno de Alba 1992: 9; Buesa Oliver y Enguita Utrilla 1992: 209; Enguita Utrilla 2004: 16).

Las investigaciones de Kabatek (2013: 27) y Arias Álvarez y Hernández Mendoza (2016: 390) explican que la tipología textual de un documento condiciona su análisis lingüístico. El siglo XVI, en América se generó un número importante de textos de distintas tradiciones discursivas, en los que se informaba personal o colectivamente sobre América. Una de estas tradiciones es lo que llamamos Crónicas de Indias (CI), denominación "que agrupa un amplio y variado conjunto de textos que versan sobre el proceso de descubrimiento, exploración, conquista y colonización del Nuevo Mundo por parte de España” (Valcárcel Martínez 1997: 11). La diversificación textual se aclara, en parte, con la clasificación de Mignolo (1982) en Cartas Relatorias, Historia y Relaciones, entendidas estas últimas como textos redactados por testigos directos o indirectos de la empresa indiana. Su propósito comunicativo es exponer, justificar o relatar ante los poderes fácticos cuestiones relativas a la exploración y colonización de los nuevos territorios.

Con respecto a los documentos coloniales del siglo XVI, las Relaciones Geográficas de Indias (RGI) son textos escritos de manera colectiva (a veces, anónima y otras, con la presencia de uno o varios autores identificados) de un modo opuesto a la individualidad que representan las CI. Además, las RGI encarnan la exigencia administrativa de información del Consejo de Indias que, ocasionalmente, aparece en alguna CI, puesto que para ejercer el asesoramiento que ofrecía al rey este organismo requería un conocimiento lo más profundo posible de los habitantes gobernados y de su territorio, con el correspondiente vocabulario que daba nombre a las cosas del Nuevo Mundo. El material que proponemos (RGI) para analizar con criterios taxonómicos, al mismo tiempo que valoramos como idóneo en un corpus de americanismos del siglo XVI, posee diferente finalidad, debido a su carácter burocrático prefijado por un cuestionario administrativo cercano al conocimiento etnográfico, con respuestas elaboradas con datos colectivos $\mathrm{y}$, muchas veces, sin autor conocido.

Relación y RGI pueden diferenciarse si establecemos que las segundas son la evolución textual de las primeras, y esto se debe al carácter híbrido que ostentan los distintos textos que se producen en el periodo colonial. La diferencia ya fue expuesta por Stoll (1998: 154), quien señala que esta se basa en que las RGI son "las respuestas que las autoridades regionales y locales hispanoamericanas dieron a unos cuestionarios confeccionados en el Consejo de Indias". Mignolo (1987), después de analizar las RGI que se generaron a partir de un cuestionario oficial desde 
1574, afirma también como rasgo diferenciador que son una producción colectiva o coral que implica en principio al rey, que requiere la información, al Consejo de Indias, que la pone en ejecución, a los escribanos y notarios públicos que escriben lo que informan los indios y los vecinos, según el mencionado cuestionario. En dicha cadena de comunicación, los que escriben son los que deciden sobre el texto final que conforma una RGI.

Al mismo tiempo, Wesch (1998: 189), Franco Figueroa (2004: 42), Bravo García y Cáceres Lorenzo (2013: 31) definen nuestro material de análisis como documentos administrativos de carácter expositivo y descriptivo, que surgen como cumplimiento de un requerimiento burocrático, por lo que en este contexto, su función es informar con objetividad; así, aunque algunas RGI muestren opiniones personales, la gran mayoría solo presentan información sobre la colonización de los españoles en tierras americanas.

La importancia de la fundamentación documental para la recuperación del léxico usado en América ha sido demostrada por estudiosos de la historia del español (Boyd Bowman 2003: en línea; Frago Gracia 1992a: 24; Franco Figueroa 2004; Sánchez Méndez 2012: 75). En cualquier caso, la recopilación de testimonios textuales es una labor que aún no se ha concluido, porque la abundancia de documentos "es una maldición y una bendición para la investigación" (Lüdtke 2014: 66). Esto supone que debe existir una selección de la base documental en la que se prioricen unos criterios frente a otros, acorde al propósito final de un corpus (Hernández 2012).

Nuestro estudio hace suya la afirmación de Bertolotti y Company (2014: 130), quienes especifican que un corpus es un conjunto de datos lingüísticos que aparecen en determinados textos seleccionados con criterios predeterminados, y con el fin de constituir la evidencia empírica. Las pautas para incorporar un documento a un corpus giran alrededor de las referencias diatópicas, diacrónicas, diafásicas y diastráticas, a las que se han añadido otros conceptos como la tradición discursiva, y la posibilidad de que la diversificación textual refleje la oralidad (Arias Álvarez y Hernández Mendoza 2012; Bertolotti y Company 2014).

Las tradiciones discursivas disponibles para la realización de un corpus en América parecen haberse especializado con respecto a la información léxico-semántica que aportan. Esto significa que cada tipo de texto asume una función comunicativa en la comunidad que se produce (Oesterreicher 2004). En esta misma línea, Bertolotti y Company (2014: 144) proponen cuatro tipos textuales o discursivos (cartas, cronísticos, jurídicos y administrativos) que representan desde lo "más privado > más público, cuyos cortes internos no tienen, como es lógico, fronteras nítidas".

En la indagación diacrónica en los corpus, la búsqueda de muestras de lengua en las que aparezca el americanismo léxico señala la necesidad del análisis taxonómico y la valoración sobre la posible idoneidad de los textos de las distintas tradiciones discursivas (en nuestro caso, las RGI) para proporcionar ejemplos de la originalidad, heterogeneidad o diversificación léxica panhispánica y regional del léxico(Carrera de la Red y Herrán Santiago 2007: 346). El escrutinio textual evidencia la diferencia en el número de americanismos léxicos; por ejemplo, el examen de las cartas corrobora que sus autores utilizan pocas voces americanas frente al gran número que exhiben los cronistas etnográficos o religiosos de este mismo periodo. A modo ilustrativo del hecho de que cada tipología textual tiene su propia tendencia a la hora de utilizar el americanismo léxico, contamos con los datos de 220 vocablos obtenidos de las cartas 
privadas de Puebla (siglo XVI) por Boyd Bowman (2003), frente a las 6.322 entradas de Sahagún en su crónica etnográfica de Historia general de las cosas de Nueva España (Bastardín Candón 2013) o los 2.422 ejemplos de las Relaciones geográficas de Venezuela (Bravo García y Cáceres Lorenzo 2013). También, Company (2012: 269) aporta referencias sobre esta cuestión, con 78 textos no literarios de Nueva España (cartas, denuncias, informes, inventarios, peticiones, testamentos, etc.) registra 31 indigenismos léxicos. Por su parte, Zamora Munné (1976: 84-87), con 48 documentos no literarios y cronistas menores de toda América colonial, recopila 231 indigenismos.

En lo que se refiere a los corpus en línea, Léxico Hispanoamericano (14931993) (Boyd Bowman 2003); Corpus Electrónico del Español Colonial Mexicano (COREECOM 2013) y el Corpus Diacrónico y Diatópico del Español de América (CORDIAM 2015) coinciden parcialmente en las pautas de selección de los documentos. Podríamos decir que el criterio general es recopilar todos los potenciales textos con el propósito de conocer "valores semánticos, su distribución geográfica, sus irregularidades gramaticales (si las hay), las principales variantes fonéticas, sinónimos y antónimos, asociaciones de palabras, y otras cosas por el estilo" (Boyd Bowman 2003: en línea). El resultado es la presencia de una base documental poco clara, ya que solo se nombra el autor y el título, por lo que será el estudioso quien necesite indagar esta cuestión, basándose en sus propias pesquisas para obtener conclusiones sobre el valor de la tradición discursiva en la que se integra. Conforme a lo expuesto anteriormente, las preguntas de investigación preliminares que nos planteamos son las siguientes: ¿qué criterios se utilizan a la hora de seleccionar una tradición discursiva para un corpus de americanismos léxicos?; y ¿cómo se cumplen en las RGI dichas pautas, al mismo tiempo que proporcionan información léxica que refleje la originalidad, heterogeneidad o diversificación léxica panhispánica y regional americana?

En esta investigación hemos optado por el análisis de las RGI, debido a que no están presentes en el COREECOM (2013) y solo aparecen parcialmente en el CORDIAM (2015), y como son corpus que están en proceso de incorporación de nuevos documentos (Arias Álvarezy Hernández Mendoza 2012; Bertolotti y Company 2014), nos cuestionamos si las RGI deben incluirse como una tradición discursiva que complementa a los que ya están registrados. Al respecto, Boyd Bowman (2003) incorpora algunas RGI, que según sus indagaciones aportan ejemplos de léxico con unos porcentajes más o menos elevados ${ }^{1}$. En esta línea, Quirós García y Ramírez

\footnotetext{
Las obras se encuentran referenciadas en Boyd Bowman (2003), y los lemas recopilados por este autor como headwords o lemas son los siguientes: Relaciones de viajes (siglo XVI, XVII, XVIII) (2.076 lemas) para varios puntos de América. Del área del Caribe continental utiliza Relaciones geográficas de Venezuela (2.422 referencias léxicas); las Relaciones de mando: memorias presentadas por los gobernantes del Nuevo Reino de Granada (2.535 lemas analizados); la Relación de visitas coloniales. Tunja (Colombia) de J. Mojica Silva (733 ejemplos). Para la zona de influencia del nahua: las Relaciones histórico-descriptivas de la Verapaz, el Manché y Lacandón, en Guatemala (1635), con (1.102 headwords); Relación de Michoacán (1541), (731 lemas); Relación breve de la venida de los de la Compañía de Jesús a la Nueva España, año de 1602, (463 entradas); Nueva colección de documentos para la historia de México (Siglo XVI). Contiene: "Relación de Tezcoco", por Juan Bautista Pomar, y "Breve relación de los señores de la Nueva España”, por Alonso de Zurita, (239 referencias). De Sudamérica: P. Pizarro, Relación del descubrimiento y conquista del Perú (690 entradas); Relación general de la villa imperial de Potosí, (405 lemas); el cronista P. Ramírez de Águila, Noticias politicas de Indias y relación descriptiva de la Ciudad de la Plata, metrópoli de las provinçias de los Charcas y Nuebo Reyno de Toledo, en las Occidentales del gran Imperio del Perú, (La Plata, 1639), (815 voces); F. Santillán, Blas Valera y Joan de Santacruz Pachacuti, Tres relaciones de antigüedades peruanas, (300 referencias); D. de Trujillo, Relación del descubrimiento del reyno del Perú, (121 headwords).
} 
Luengo (2015: 197) recomiendan la reflexión "acerca de la misma constitutio corporis y de las características lingüísticas que identifican a los materiales que componen los diversos corpus de trabajo".

\section{Marco Té́RICO}

Un estado de la cuestión de la bibliografía permitirá delimitar el problema de investigación.

\subsection{Criterios usados para la creación de un corpus}

El cumplimiento de los criterios seguidos en la selección de documentos para la historia de español americano nos proporciona unas pautas básicas generales, al mismo tiempo que convierte a una determinada tradición discursiva en un material adecuado para implementar un corpus sobre la historia de la incorporación del léxico del español. Estos criterios son los siguientes:

2.1.1. Primer criterio. Textos escritos originales en lengua española, redactados por autores que tienen una experiencia americana o no, pero que informen o describan sobre la realidad americana, independientemente del lugar en el que se publiquen (Hernández 2012). La posibilidad de contar con originales hace viables investigaciones sobre la información que aportan las grafías acerca del estado de la lengua o sobre el grado de asimilación y adaptación en el español (Conteras Seitz 2013; Bertolotti y Company 2014). Además, facilita el reconocimiento de la correspondencia entre voces que no aparecen castellanizadas y el grado de asimilación lingüística de un vocablo (Moreno de Alba 1992; Franco Figueroa 2004; Cáceres Lorenzo 2014).

También es deseable que los documentos no sean "datos fragmentados, inconexos o de textos incompletos" (Parodi 2008: 96), sino que se seleccionen textos que preserven las unidades de sentido y la función comunicativa. El soporte documental clasificado por Arias Álvarez y Hernández Mendoza (2012: 10) se estructura en formales, semiformales e informales, subdividiendo estos tipos en variedades textuales relacionadas con el concepto de tradición discursiva de Oesterreicher (2004) y Biber (1993). Por su parte, el CORDIAM (2015) determina la recopilación de textos no literarios y no periodísticos y se propone la inclusión de fuentes documentales administrativas, cronísticas, jurídicas y de particulares, porque se ha tenido en cuenta la circulación pública o privada del documento (Bertolotti y Company 2014: 130).

2.1.2. Segundo criterio. Escritos en los que se constate la información diacrónica, lo que implica que "hace falta disponer de una documentación más amplia, como la que es propia de un diccionario histórico, pues no se trata de documentar solamente los puntos de partida y los puntos de llegada, sino los hitos del proceso" (Rivarola 2001: 30). El hecho de contar con abundantes textos de distintos años hace posible que el corpus sea representativo, porque "a corpus is put together in a principled way as to be representative of a larger textual population, in order to make it possible to generalize findings concerning that population" (Biber 1993: 243). Kabatec (2013: 25) duda de la posibilidad de una representatividad práctica, pero concluye que "lo que (teóricamente) podría existir es una cierta representatividad cualitativa: un corpus con (casi) toda la gama de posibilidades de una lengua en un momento dado". 
2.1.3. Tercer criterio. Estos documentos aportan datos geográficos que complementen a las otras dimensiones presentadas. Tanto Boyd Bowman (2003) como el COREECOM (2013) y el CORDIAM (2015) hacen hincapié en la necesidad de conocer la información diatópica con el fin de valorar la difusión de los vocablos. La heterogeneidad léxica de las hablas se evidencia en esta cuestión. El registro de una voz en una determinada área lingüística puede señalar la evidencia de un vocablo dialectal (Rona 1969: 135). Dicha peculiaridad puede ser de tipo fonético, sintáctico o léxico- semántico (Ávila 1998: 9). Según esto, la información diatópica del localismo dialectal es un indicador del grado de originalidad interna del léxico de una determinada comunidad de hispanohablantes (Sala et al. 1982; Lope Blanch 1994).

Al mismo tiempo, muchos americanismos (indígenas y patrimoniales) adquieren una difusión más extensa hasta llegar a ser panhispánicas, porque "aparecen en más de tres países hispánicos y no estuvieron afectados por restricciones diafásicas, diastráticas o de vigencia" (DRAE 2014: Preámbulo).

2.1.4. Cuarto criterio. Manuscritos que muestren información sociocultural, porque la nueva documentación recopilada refleja la sociedad que los genera, en concreto, el origen de los autores, grupos humanos y sociales (Frago Gracia 1992b: 399; Company 1994: 6). Este criterio ofrece ciertas dificultades porque la investigación diacrónica se fundamenta en fuentes de información de los que saben escribir (Oesterreicher 2004), no de toda la sociedad. El vínculo entre vocabulario cotidiano de los territorios españoles en América y los textos administrativos fue apuntado por Wesch (1998: 189), Contreras Seitz (2011: 46) y Bravo García y Cáceres Lorenzo (2013). De hecho, en su análisis "podemos descubrir, detrás del formulismo jurídico, valiosas indicaciones del lenguaje espontáneo de antaño, entre ellas ejemplos tempranos de diferencias regionales" (Boyd Bowman 2003: en línea).

La dimensión diafásica que define el vocabulario se materializa en la tradición discursiva, esto supone reconocer que esta "es más que un simple enunciado, es un acto lingüístico que relaciona un texto con una realidad, una situación, etc., pero también relaciona ese texto con otros textos de la misma tradición" (Kabatek 2005: 151). En el caso de los testimonios textuales burocráticos, la finalidad es la comunicación entre la administración y los ciudadanos. Esto exige el uso de un lenguaje comprensible, salvo inevitables tecnicismos, para todos los miembros de la comunidad (Zamora Munné 1976: 107). Los textos originales de naturaleza administrativa, que se guardan en los archivos, suministran información lingüística a los filólogos (Frago Gracia 1992a; Lope Blanch 1994). Al mismo tiempo, parece necesario comprobar el grado de oralidad que exhibe cada tradición discursiva que puede estar vinculado a la cotidianeidad (Eberenz 2003: 65).

Los estudios de dialectología histórica del español colonial requieren indagar sobre el léxico americano panhispánico y diferencial (Moreno de Alba 1992; Enguita Utrilla 2004), y esto supone la valoración real del vocabulario americano en las distintas tradiciones discursivas. Nos referimos a la presencia en los textos de los indigenismos, como préstamo general o local en la lengua española, y los procesos de acomodación americana del léxico español tradicional (Franco Figueroa 2004; Cáceres Lorenzo 2013 y 2014). Por ejemplo, tanto el COREECOM (2013) como el CORDIAM (2014) están aún en fase experimental e intentan incorporar las investigaciones más recientes con respecto a la lingüística de corpus. En el caso 
del COREECOM (2013) se habla de incluir los parámetros diatópicos, diacrónicos, diastráticos (grupo étnico-social y el género-sexo del autor), y, recientemente, los creadores de este corpus han añadido que el conocimiento de la lengua está vinculado a las tradiciones de los textos, "ya que un tipo de texto condiciona o puede condicionar la selección de determinados elementos o fenómenos lingüísticos" (Arias Álvarez y Hernández Mendoza 2016: 390).

\subsection{La novedad de las RGI en la tradición discursiva de los textos administrativos}

Las RGI materializan el proceso burocrático de recogida de información de un texto administrativo colonial, lo que demuestra la acuciante necesidad de información del Consejo de Indias, pues para gobernar acertadamente se necesitaba un conocimiento lo más profundo posible de los grupos humanos de cada territorio americano. Según Solano (1988), la primera solicitud de información se inicia en 1530 , pero no será hasta el último tercio del siglo XVI cuando exista un cuestionario oficial. El periodo de 1577 y 1586 es el de mayor número de solicitudes, de hecho, quinientas comunidades americanas escriben RGI para proporcionar información a los poderes fácticos.

La estructura para la redacción de una RGI estaba fijada por un cuestionario con vocación etnográfica descriptiva, elaborado desde la metrópoli que interrogaba sobre distintos ámbitos de la sociedad en América (vid. Instrucción y memoria de las relaciones que se han de hacer para la descripción de las Indias 1577): el nombre de la comarca o provincia, ubicación, significado de los topónimos, "el temperamento y calidad" de la tierra; también "si es llana o áspera, rasa o montosa, de muchas o pocas fuentes, y abundosa o falta de aguas, fértil o falta de pastos, abundosa o estéril de frutos, y de mantenimientos", etc.; las materias primas de las que dispone, su rendimiento económico, la organización social, distancia entre pueblos, la salud y la enfermedad, las costumbres, el proceso de evangelización, las lenguas indígenas que se hablan, el comportamiento de los indios, etc. (Solano 1988: xix).

En este punto, es viable afirmar que el vocabulario que aparece en las RGI es la designación socialmente aceptada en cada territorio americano. Las RGI se caracterizan por ser documentos oficiales, en los que se encuentra con frecuencia el detalle y la profundidad de los contenidos solicitados (Alvar 1972). Por su parte, Cáceres Lorenzo (2013: 63) sostiene que "es posible aseverar que las Relaciones Geográficas de las distintas zonas interactúan con la sociedad para dar información a través de la encuesta". En palabras de Contreras Seitz (2011: 46), los textos coloniales, muchas veces, muestran referencias sobre el desarrollo del gobierno de aquellos territorios, y además, "asuntos mucho más cotidianos que forman parte de las redes sociales que se van tejiendo en torno de los individuos y de los grupos que componen dicha sociedad".

Las RGI representan un método de indagación gubernamental que se plasmaba en un texto redactado de manera colectiva, del que fueron responsables las autoridades americanas (civiles y religiosas, los funcionarios subalternos y los mismos habitantes que, ocasionalmente, aparecen en alguna RGI). Las autoridades estaban comprometidas en registrar, recolectar y remitir los datos que, posteriormente, serían procesados en las instituciones metropolitanas (Jiménez de la Espada 1965; Mignolo 1980, 1987; Oesterreicher 2004; Cáceres Lorenzo 2013). 


\section{Objetivos}

El problema de investigación planteado en este trabajo sobre de la necesidad de conocer las características taxonómicas de las RGI entre los textos coloniales y la posible inclusión de estas en un corpus en que se obtengan datos sobre el americanismo léxico, nos lleva a proponer los siguientes objetivos:

1. Examinar si las RGI seleccionadas como estudio de caso cumplen los criterios que ya han sido analizados en otros textos coloniales: textos no fragmentados de una tradición discursiva, con información de las variables diacrónica, diatópica, diafásica y diastrática. La importancia de este examen hará posible reconocer si las RGI como material textual empírico proporcionan datos sobre una nueva función comunicativa y discursiva, además de los factores que advierten sobre los ejes en los que se ordenan los idiolectos o lenguas individuales del español americano en el siglo XVI.

2. Valorar el léxico americano que las referidas RGI presentan con respecto a otras tradiciones discursivas. Esta información permitirá a los autores que construyen corpus y al investigador especializado la obtención de una visión de conjunto en el uso del vocabulario, además de justificar los factores extralingüísticos que condicionan al americanismo léxico (préstamos, nuevos significados, etc.) presente en cada texto colonial en un universo, aún mayor, formado por los tipos textuales cronísticos, administrativos, jurídicos y de particulares, en el que cada tipología textual aporta un contexto discursivo distinto.

El análisis de las RGI seleccionadas entre 1546-1597 constituye ciertamente una aportación, como también lo manifiestan Quirós García y Ramírez Luengo (2015: 197), quienes subrayan "la capital importancia que tiene la tipología textual en los trabajos sobre la historia del léxico americano, así como la necesidad que se presenta para los estudiosos de tener en cuenta tal circunstancia a la hora de interpretar los resultados".

\section{Material y Método}

El escrutinio del vocabulario americano y de los criterios de las RGI se realiza después de un proceso de recopilación selectiva. Los textos seleccionados son aquellos que responden a los criterios de variación geográfica y cronológica de América durante el siglo XVI, pero, sobre todo, que han sido cotejados con el original para verificar que no han sido retocados, según la referencia bibliográfica de los compiladores. Aunque en este trabajo no analizamos las grafías, hemos querido seguir el primer criterio. La ordenación cronológica se muestra a continuación en la Tabla 1:

Tabla 1. Presentación diacrónica de las RGI

\begin{tabular}{|l|l|}
\hline 1. Cumaná (Arellano Moreno, 1964: 3-14) & 1546 \\
\hline 2. Antioquia (Patiño, 1983: 23-103) & $1559-1560$ \\
\hline 3. Darién (Patiño, 1983: 105-112) & 1571 \\
\hline 4. S. Cruz de la Sierra (Jiménez de La Espada, 1965: 407-409) & 1571 \\
\hline 5. Potosí (Jiménez de La Espada, 1965: 357-361) & 1572 \\
\hline
\end{tabular}




\begin{tabular}{|l|l|}
\hline 6. S. Fe de Bogotá (Patiño, 1983: 113-137) & 1572 \\
\hline 7. Zimapán (Acuña, 1985a: 99-104) & 1579 \\
\hline 8. Nexapa (Acuña, 1984: 345-360) & 1579 \\
\hline 9. Antequera (Acuña, 1984: 31-42) & 1580 \\
\hline 10. Juxtlahuaca (Acuña, 1984: 281-324) & 1580 \\
\hline 11. Veracruz (Acuña, 1985b: 343-374) & 1580 \\
\hline 12. Tétela (Acuña, 1986: 265-276) & 1581 \\
\hline 13. Jauja (Jiménez de La Espada, 1965: 166-175) & 1582 \\
\hline 14. Puerto Rico (Alatorre, 191: 35-55) & 1582 \\
\hline 15.Tucumán (Jiménez de La Espada, 1965: 390-396) & 1583 \\
\hline 16. La Paz (Jiménez de La Espada, 1965: 342-351) & 1586 \\
\hline 17. El Dorado (Arellano Moreno, 1964: 247-257) & 1597 \\
\hline 18. Guayaquil-Quito (Jiménez de La Espada, 1965: 121-143) & s. f \\
\hline 19. La Plata (Jiménez de La Espada, 1965: 352-356) & s. f. \\
\hline 20. Lima (Jiménez de La Espada, 1965: 153-154) & s. f. \\
\hline
\end{tabular}

La ordenación cronológica se complementa con la distribución geográfica de las veinte RGI que se muestra en esta Figura 1. En este caso se han considerado las distintas regiones de influencia de las lenguas indígenas consideradas de mayor difusión: caribe, nahua y quechua:

Fig. 1. Distribución diatópica

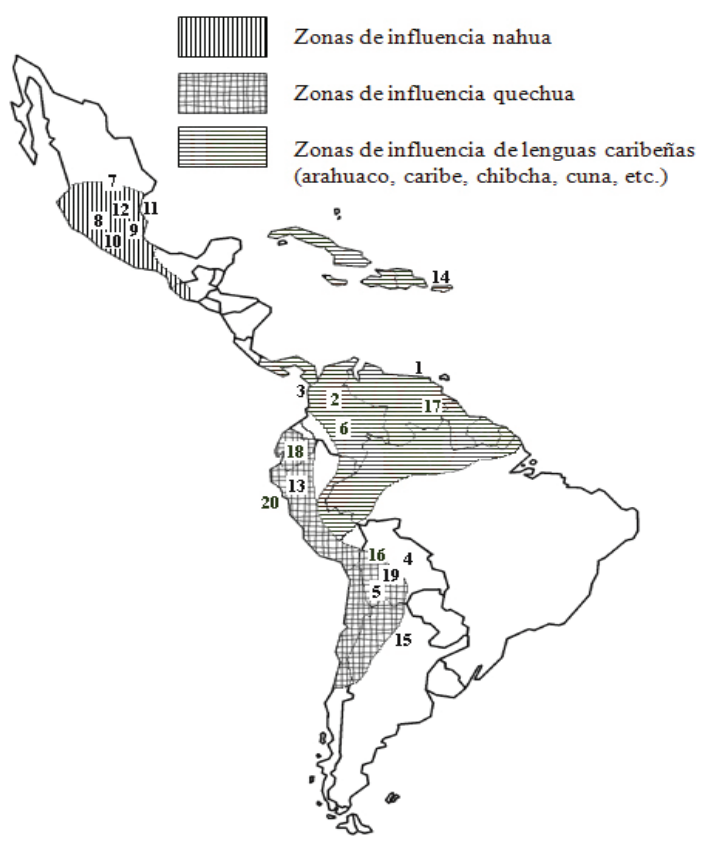


Una vez reunido el soporte documental, y con el fin de mostrar los resultados léxicos, en este corpus hemos recogido, hasta conformar un lexicón, todos los indigenismos léxicos y los lexemas de procedencia española, con cambio o especificación de contenido semántico con respecto al español europeo (Company 2010). Para fijar el origen de todas las palabras y su uso americano se han utilizado Company y Melis (2002), Boyd Bowman (2003), DA (2010) y DRAE (2014), diccionarios que confirman la introducción de estas voces en el nivel panhispánico y/o regional. También se consultó Andión Herrero (2002) y Torres Torres (2004). A esta fase de recopilación y determinación le sigue la clasificación y cuantificación de los ejemplos, con el fin de dar respuestas a las preguntas de investigación de este trabajo.

\section{Resultados y Discusión}

Las RGI están escritas en español, porque la misma finalidad comunicativa burocrática de estos textos no hace posible la incorporación de otras lenguas. Ahora bien, tal como se observa en la Tabla 2, no todas las RGI tienen datación cronológica (Jiménez de La Espada, 1965; Acuña, 1985a, 1985b). Esto puede ser un obstáculo a la hora de fijar de manera empírica cualquier vocablo (Rivarola 2001). Tampoco parece que todas las RGI conserven sus originales, aunque en la selección de esta investigación se han escogido aquellas que sí presentaban esa posibilidad.

Asimismo, las RGI cumplen las características de la tradición discursiva administrativa, por lo que estos textos originales proporcionan información diafásica de este registro. El trabajo de Wesch (1998) insiste en que son textos comprensibles por el mayor número de individuos, porque el lenguaje de la administración implica una aceptación social y designa lo cotidiano. En palabras de Bertolotti y Company (2014: 143), con referencia a los textos administrativos: "básicamente, dan cuenta del mundo en que un individuo se mueve cotidianamente y de las instancias que regulan esa cotidianeidad e interacción oficial entre personas".

La información diastrática y diafásica de una RGI es una realidad compleja. La nómina de personas que están implicadas en el proceso de redacción de una RGI (autoridades, funcionarios o particulares civiles o religiosos, informantes indios, intérpretes y escribanos) involucra a diferentes grupos humanos (españoles, criollos e indios), pero sin una referencia clara de la aportación de cada uno. De igual forma, es posible que, como indica Mignolo (1987: 457), las RGI sean la consecuencia del control de los españoles sobre la información, por lo que estas descubren las voces que los españoles seleccionan e identifican en el vocabulario de la sociedad colonial.

En lo que se refiere al número de americanismos, las RGI de nuestra investigación muestran el léxico tanto el de uso general como la riqueza léxica regional. En la Fig. 2 se exhiben los datos cuantitativos que evidencian esta cuestión: 
TAXONOMÍA DE LOS DOCUMENTOS DEL SIGLO XVI: LAS RELACIONES GEOGRÁFICAS DE INDIAS PARA UN CORPUS SOBRE AMERICANISMOS LÉXICOS

Fig. 2. Diferencias geográficas y cronológicas en nuestro corpus
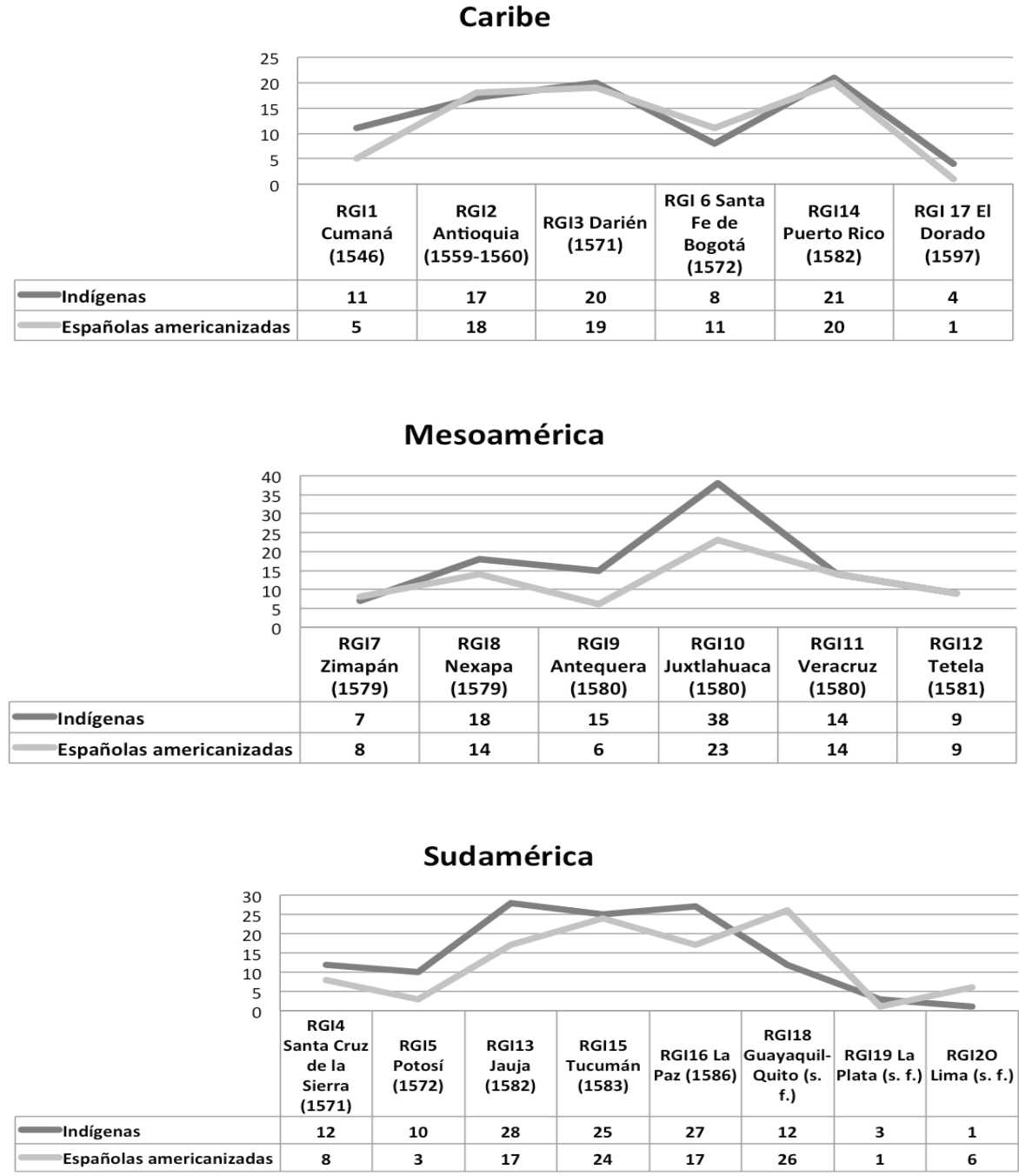

Los resultados obtenidos explican que las RGI del área caribeña son las que menos voces americanas (de origen indígena o español) utilizan ${ }^{2}$, seguidas de cerca

\footnotetext{
En la RGI de Cumaná (Venezuela) se registran del Caribe (1546): canoa, caricari, danta, hamaca, jagüey (Panamá), macana, maiz manatí, sabana, totuma y yuca. Los términos españoles que hacen referencia a una Nova Realia son ciénaga para designar un depósito natural, los animales tigre y venado, y de tipo económico y social: peso 'moneda' $y$ rescate 'baratijas'. Los redactores de la RGI de Antioquia (Colombia, 1559) utilizaron las voces antillanas arcabuco, bijaos, bohio, cabuya, cacique, caimán, canoa, caribe, chaquira, hayo, jagüey, maiz, sabana y yuca. Además del nahuatlismo cacao y los quechuismos coca y papa. La voz patrimonial alzado 'sublevados' referido a los indios, la descripción de la naturaleza (nombres geográficos y animales conocidos por lo europeos antes de llegar a América, etc.): balsa árbol con el que se construye una balsa', cascajo 'conjunto de piedras', ciénaga, estancia 'finca agrícola', gorriones, grano, tomín (estos dos últimos para referirse a medidas), hierba (genérico), leones,
} 


\section{por las sudamericanas ${ }^{3}$. Con respecto a las del área mesoamericana la cantidad de vocablos es mayor ${ }^{4}$,}

páramo, quebrada 'arroyo', ranchería (derivado), rozas 'terreno cultivado', tominejo 'colibrí', tigre y venado, además de capitán 'tipo de pescado' y encomendero (derivado). En Darién (Panamá, 1571) hemos encontrado la voz quechua papa y los antillanismos ají, arcabuco, bahareque, bejuco, bohío, cabuya, cacique, caimán, chicha, cura, guaduas, guama, guayaba, maíz, nigua, pitahaya, sabana, tuna y yuca. Lexías del español meridional: bizcocho 'torta', capitán 'pez', cascabel 'serpiente', encomendero, estancia, león 'para designar a un felino de América', machetones 'árbol', moscada 'variedad americana de la designación española', calandria 'ave', páramo, puerco salvaje 'sustantivo + salvaje', construcción americana para designar realidades de América', quebrada, tabaco, tigre, venado y zarzamora. También hemos hallado vocabulario del Caribe en S. Fe de Bogotá (1572): bijao, bohio, cacique, canoa, caribe, maiz y sabana. Asimismo, se registran voces consideradas americanismos alzado, bravo, ciénaga, encomienda, encomendero (derivado), hoyar 'hacer hoyos', perulera 'guayaba silvestre', peso, tomin y viático 'ayuda'. En P. Rico (1582), todos los vocablos son del Caribe: anona, batata cacique, canoa, capá, caribe, cazabe, ceiba, conuco, danta, guayaba, guayacán, guayabo, huracán, maga, maíz, mamón, maní, piragua, pitahaya y tabonuco. Con respecto a voces españolas: alzado, arrecife, bajo 'terreno acuático', bálsamo 'arbusto', blandura 'humedad', bravo, cardón, coco 'voz creada en América', estancia, hacienda, higuillo pintado (diminutivo + adjetivo, mecanismo de nueva designación), manzanilla, palo santo (sustantivo + adjetivo), piña, quebrada, romadizo 'árbol', sábila 'aloe americano', tabaco, trapiche (léxico caña de azúcar' y yerba de S. María (hiperónimo + complemento). El Dorado (1597) muestra los indigenismos: caribe, cazabe, hamaca y piragua; y la voz patrimonial, rescate.

3 Los quechuismos de Santa Cruz de la Sierra (1571) son lúcuma, mate y zapallo, la palabra guaraní tapera se utilizan junto a las antillanas anta, guayaba, guayacán, maíz, maní, mico y toceñe. Con respecto a los americanismos de origen español, botija, calabazo, garrobilla, granadilla (estos dos últimos como ejemplos de diminutivos que incluye una marca de referencia semántica nueva), higos del mastuerzo (hiperónimo + complemento), pava, piña y tigre. En Potosí (1572) anotamos aillo, caracará, guaca, guayaca, inga, quinua, soroche, yanacona y zapallo. Además, de ejemplos de gran difusión en otras RGI: leones, ranchería (derivado), y rescate. La RG de Jauja (Perú) recoge los siguientes indigenismos de la zona inca: alpaca (aimara), aillo, chácara, coca, curaca, guaca, guanaco, inca, mashua, oca, papa, puna, quichua, quinua, tambo, vicuña, vizcacha y yanacona. Los antillanismos son aji, bohio, cacique, chaquira (cuna), guabas, guayaba (arahuaca), hamaca, maíz y maní. Extrañamente emplea el nahuatlismo aguacate, en lugar del quechuismo palta. De nuevo, hallamos voces de gran uso en esta centuria: arveja, bagre 'pez', balsa, encomendero, encomienda, frijol, granadilla, durazno, ladino, leoncillos, piña, quebrada, rescate, romadizo, tabaco, tomin y venado. En la RGI de Tucumán, según el DA (2010) y DRAE (2014), se registran lexías de origen incierto: cebil, diaguita, taruga, tonocoté y sanavirón. También, los quechuismos: chacra, chañar, guanaco, inga, papa, puna, quinua, vicuña, vizcacha y zapallo, y las voces antillanas cabuya, cacique, canoa, chaquira, jagüey, maiz, sabana, tuna, yuca, y el nahuatlismo tule. Los ejemplos de procedencia española son de diferentes áreas temáticas: algarroba 'árbol americano', armadillo 'creación desde armado para designar a un mamífero', bagre, balsa, bañado 'terreno húmedo', bravo, cardón, cochinilla, durazno, encomendero, estero 'riachuelo', galápago, gallo de papada (hiperónimo + complemento), gorrión, grana, herbaje (derivado), ladino, león, páramo, pava, tigre, venado y zaíno 'mamífero'. En La Paz (1586) encontramos las voces nahuas camagua y guaje, los antillanismos aji, cacicazgo, cacique, chaquira, maíz, y vocablos del área inca aíllo, aimara, chuco, chuño, coca, cuy, curaca dije, guaca, guanaco, inga, llama, molle, oca, palta, papa, quichua, quinua, tambo, vicuña y yanacona. Además de alfajía 'listón de madera', aguada 'abrevadero', ciénaga, durazno, encomendero, estancia, leones, quebrada, piña, romadizo, tabaco, tigres, trapiche, turbión 'riada', y venado. En las tres últimas RG sin fecha hemos podido inventariar en Guayaquil-Quito: aji, cabuya, cacique, caimán, chaquira, guaba, guaca, locro, maguey, maiz, tambo y vizcacha junto a aldaba 'parte de una puerta', amiga 'amigo cercano', bagre, balsa, barral, ciénaga, compadre, cuadra 'distancia que va de una esquina a la siguiente', durazno, encomendero, gorrión, ingenio, ladino, lajas, lisas, pavas, penca, peso, quebrada 'arroyo', regalado, tollo, tomín, tortilla, venado, zancudo 'ave', y zarzaparrilla 'arbusto'. En La Plata leemos canoa, maíz y el gentilicio quechua chiriguano, y la voz peso; y, por último, en esta RG de Lima solo se usa el indigenismo maiz; además de bagre, callao, cañaveral, cimarrón, corambre 'relacionado con las pieles', y encañada 'terreno entre lomas'.

4 Registramos en Zimapán (1579), maguey y maiz (antillanismos) y chile, cimatl, coyote, mexicana y mezquitl (nahuatlismos). También, designaciones de la naturaleza, bravo, caliche, frijol, gallina montesa ‘sustantivo + montés, construcción americana para designar realidades de América', ladino, leones, margarita y venado. Con igual fecha en Nexapa las lexías mesoamericanas (cacao, camalote, chichicastle, chontal, copal, guaje, henequén, maxtle, mexicana, olote, piciete y zenzontle) alternan con las caribes (aji, aura, danta, iguana, macana y maíz). Además de algarroba, armado, brasil, encino, estancia, gorriones, grana, hacienda, leones, rumbeada (derivado), tabaco, tigre, tortilla y zarzaparrilla. En Antequera (1580), las voces del Caribe (ají, guayaba, maíz, mamey, naborías y tuna) junto a los nahuatlismos (aguacate, cacalosúchil, cacao, chahuite, chía, nopales y tomate). Solo aparece del quechua el término molle. Los americanismos transformados desde el español son: bravo, ciénaga, estancia, grana, morillo 'material de construcción', rescatar y turbiones 'riadas'. La RGI de Juxtlahuaca en Oaxaca (1580) utiliza muchos 
a pesar de que es superior el número de RGI de Sudamérica. En todas las zonas se utilizan en total 279 vocablos, el uso de voces de los autóctonos y las de origen español es similar en muchos casos. Así 11 (Veracruz) y 12 (Tétela) en las RGI del área mesoamericana, 3 (Darién) y 14 (Puerto Rico) en el Caribe; 15 (Tucumán) y 16 (La Paz) en la zona inca. En contrapartida, las RGI 17 (El Dorado) y 20 (Lima) de distintas áreas revelan una fuerte diferencia. En estas 20 RGI, los indigenismos léxicos suman 155 muestras y las voces españolas americanizadas, 124 ejemplos.

Este resultado se entiende mejor en comparación con los datos sobre el léxico en documentos de diferentes tipologías, aportados por Zamora Munné (1976), Boyd Bowman (2003), Company (2012), Bastardín Candón (2013), Bravo García y Cáceres Lorenzo (2013). En nuestra indagación, solo las RGI de la zona de Nueva España presentan 99 ejemplos de indigenismos. La comparación de datos evidencia la profusión de ejemplos léxicos en las RGI.

En lo que se refiere a los datos obtenidos con las voces españolas americanizadas, estos resultados de los 124 ejemplos obtenidos en las veinte RGI analizadas se pueden unir a los trabajos de Andión Herrero (2002) y Torres Torres, (2004).

\section{Conclusiones}

En esta investigación ha quedado demostrada la novedad e idoneidad de las RGI para su posible inclusión en un corpus sobre el léxico americano. La descripción taxonómica de las RGI indica que son textos no fragmentados de una tradición discursiva, de los que disponemos de referencia diacrónica, registro diatópico e información diafásica y diastrática que informan sobre la oralidad. Asimismo, nuestro análisis muestra que las RGI están escritas en lengua española, pero no todas disponen de un original y, ocasionalmente, carecen de una fecha.

Es decir, los dos criterios que no hemos podido confirmar plenamente son los que se refieren a aspectos relacionados con la cronología y la información sociocultural. Asimismo, hemos constatado que no siempre las RGI aparecen con una fecha concreta (por ejemplo, RGI 18. Guayaquil-Quito; RG I19. La Plata; RG I20. Lima). Esto puede traer como consecuencia que no todas puedan ser incluidas en un corpus con el indicador cronológico de un determinado proceso lingüístico. A pesar de esto, el número de ejemplos de americanismos léxicos es abundante, además de la

indigenismos nahuas (aguacate, amole, camote, capulin, chalchihuites, chile, coyote, cueitl, henequén (maya), huipil, macegual, maxtle, mexicana, nahua, ocote, otate, petate, piciete, pulque, sicu, tameme, tuza y zapote). El número de antillanismos es inferior (aji, aura, batata, cacica, cacicazgo, cacique, coa, danta, embijado, guayaba, iguana (arahuaca) macana, maguey, maiz y mameyes). En cuanto a las voces españolas que en América designan otra realidad (que ya aparecen en las otras RGI): bagre, camarones, carrizo 'planta', ciénaga, cuadrar, encino, encomendero (derivado), galápago, gavilán, gorriones, leones, lisa, madroño, pechuguera, pepita, piña, rajas, pino, ramón, romadizo, sabino, saetilla, tigre y venado. En el mismo año, anotamos en la RGI de Veracruz vocablos mexicanos (aguacate, cacahuatal (indigenismo que se muestra como un derivado), capulín, chile, cocoliste, mexicana, pita, xacal y zapote), del área caribeña (guacamaya, maguey, maíz, mameyes y tuna); y los términos americanizados: arrecife, bobo 'pez', corvinera, durazno, encomendero, estancia, gallipavo (creación americana de gallo + pavo), león, malpaís, puerco montés 'sustantivo + salvaje', quebrada, tigre, venado y zarzaparrilla. En la RGI del estado de Puebla, Tétela (1581), se utiliza para responder al cuestionario: aguacate, chía, chile, henequén, huautli, mexicana y nahuatlato (nahuatlismos), bohio y maiz (antillanismos) junto a los americanismos de procedencia española: armado, bravo, cimarrón, duraznal (derivado), encomienda, estancia, peso, quebrada y rescatar. 
novedad que proporciona el carácter plural de su proceso de redacción frente a la de otros textos coloniales.

En lo que se refiere al criterio de que las RGI reflejen un vocabulario cotidiano, estudios anteriores han afirmado esta posibilidad (Alvar 1972; Wesch 1998; Franco Figueroa 2004; Bravo García y Cáceres Lorenzo 2013). Conforme a lo anterior, pensamos que los resultados obtenidos corroboran esta cuestión, porque registramos un glosario de americanismos que muestran voces diferenciales y otras comunes. Asimismo, el aporte indígena "debe interpretarse, sin duda, como el más temprano testimonio de diferenciación regional del español americano" (Enguita Utrilla 2004: 17). Estos resultados pueden ser complementarios a los que presentan los cronistas de Indias, en los que como dice Moreno de Alba (1992: 14), estos autores de las CI se veían obligados a incluir indigenismos léxicos, que no usaban los españoles, por la naturaleza misma y el contenido del texto cronístico.

En definitiva, este artículo corrobora el aporte original de las RGI, por su carácter de textos administrativos y descriptivos redactados de forma colectiva en una clasificación taxonómica general de los documentos coloniales, además de insistir en la posibilidad de reconocer el americanismo léxico en un contexto discursivo nuevo. Con esta investigación se abre una línea de indagación con otras tipologías de documentos que confirmarán si es posible clasificar los textos con respecto a la capacidad para facilitar ejemplos de heterogeneidad y riqueza léxico-semántica.

\section{OBRAS CITADAS}

Acuña, René (ed.). 1984. Relaciones Geográficas del siglo XVI: Tlaxcala. México: UNAM. 1985a. Relaciones Geográficas del siglo XVI: México. Tomo 1. México: UNAM. 1985b. Relaciones Geográficas del siglo XVI: México. Tomo 2. México: UNAM. 1986. Relaciones Geográficas del siglo XVI: México. Tomo 3. México: UNAM.

Alvar, Manuel. 1972. "Las Relaciones de Yucatán del siglo XVI". Revista de Filología Española 55: 1-34.

Andión Herrero, M. Antonieta. 2002. Americanismos (no indígenas) en la Historia de las Indias de Fray Bartolomé de las Casas. Madrid: UNED.

Arellano Moreno, Antonio. 1964. Relaciones Geográficas de Venezuela. Caracas: Biblioteca de la Academia Nacional de la Historia.

Arias Álvarez, Beatriz y Juan Antonio Hernández Mendoza. 2013. "Importancia de la incorporación de los parámetros diastráticos y diafásicos en la elaboración del corpus electrónico del español colonial mexicano". Scriptum Digital 2: 5-20.

2016. "Argumentos dialectológicos y sociolingüísticos que Ayudan a la Caracterización del español en La Nueva España en el siglo XVI". Lingüística de corpus y lingüística histórica iberorrománica. Ed. Johannes Kabatek. De Gruyter. 385-400.

Ávila, Raúl. 1998: "Españolismos y mexicanismos: hacia un diccionario internacional de la lengua española". Nueva Revista de Filología Hispánica 46, 2: 395-406.

Bastardín Candón, Teresa. 2013. Vocabulario indígena en la Historia de fray Bernardino de Sahagún. Frankfurt am Main: Peter Lang.

Bertolotti, Virginia y Concepción Company. 2014. "El corpus diacrónico y diatópico del español de América (CORDIAM). Propuesta de tipología textual". Cuaderno de la ALFAL 6: $130-148$.

Biber, Douglas. 1993. "Representativeness in corpus design", Literary and Linguistic Computing 8: 243-257. 
Boyd Bowman, Peter. 2003. Léxico Hispanoamericano (1493-1993). Eds. Ray Harris-Northall y John Nitti. [CD-ROM]. Nueva York: Hispanic Seminary of Medieval Studies. [https:// textred.spanport.lss.wisc.edu/lexico_hispanoamericano/]

Bravo-García, Eva y M. Teresa Cáceres-Lorenzo. 2013. El léxico cotidiano en América a Través de las Relaciones Geográficas de Indias (Tierra Firme y América del Sur, s. XVI). Frankfurt am Main: Peter Lang.

Buesa Oliver, Tomás y José M. Enguita Utrilla. 1992. Léxico del español de América. Su elemento patrimonial e indigena. Madrid: Fundación MAPFRE.

Cáceres Lorenzo, M. Teresa. 2013. "Tipos de Relaciones Geográficas en el siglo XVI". Crítica Hispánica 35.1: 45-61.

2014. "Differentiation between indigenous loanwords in the Spanish American lexicón". Bulletin of Hispanic Studies 91.2: 117-126.

Carrera de la Red, Micaela y Andrea Herrán Santiago. 2007. "Oralidad en el universo de los discursos jurídico-administrativos en la Nueva Granada del siglo XVIII". Discurso y oralidad: homenaje al profesor José Jesús de Bustos Tovar 1: 333-349.

Company, Concepción. 1994. Documentos lingüisticos de la Nueva España. Altiplano central. México: UNAM.

2010. Diccionario de Mexicanismos. México: Siglo XXI.

2012. "El español del siglo XVIII. Un parteaguas lingüístico entre España y México". El español del siglo XVIII. Cambios diacrónicos en el primer español moderno, Bern: Peter Lang, 255-291.

Company, Concepción y Chantal Melis. 2002. Léxico histórico del español de México. México: Universidad Nacional Autónoma de México.

Contreras Seitz, Manuel. 2011. "Escritura en los inicios del Reino de Chile. La Crónica de Vivar". Estudios Filológicos 47: 45-57.

COREECOM 2013. = Corpus Electrónico del Español Colonial Mexicano [http://www.iifl. unam.mx/coreecom].

CORDIAM 2015 = Corpus Diacrónico y Diatópico del Español de América [http://www. cordiam.org].

DA 2010, Asociación de Academias de la Lengua Española. 2010. Diccionario de Americanismos. Madrid: Santillana.

DRAE 2014, Real Academia Española. Diccionario de la lengua española. Madrid: Espasa.

Eberenz, Rolf. 2003. "Huellas de la oralidad en textos de los siglos XV y XVI". Textualización $y$ oralidad 2: 63-86.

Enguita Utrilla, José M. 2004. Para la historia de los americanismos léxicos. Frankfurt: Peter Lang.

Frago Gracia, Juan A. 1992a. "Estrategias para la investigación en el español americano hasta 1656". Congreso de Sevilla La Lengua española: unidad y diversidad, [http://cvc.cervantes.es/congresos/sevilla/unidad/ponenc_gracia.htm,]. 1992b. "Variación dialectal y sociocultural en la documentación indiana del siglo XVI". Revista de Filología Española 3-4: 399-428.

Franco Figueroa, Mariano. 2004. "Una cala léxica en las relaciones de Indias (AGI: Charcas y el Río de la Plata. Siglo XVI)". Boletín de Filología, XL: 39-62

Hernández, Esther. 2012. "En torno a la selección y la edición de documentos para un corpus histórico de textos del español americano", Nuevas perspectivas para la edición y el estudio de documentos hispánicos antiguos, Bern: Peter Lang: 260-269.

Instrucción y memoria de las relaciones que se han de hacer para la descripción de las Indias, que Su Majestad manda hacer para el buen gobierno y ennoblecimiento de ellas (1577). [http://www.biblioteca.tv/artman2/publish/1577_381/Instrucci_n_y_memoria_de_las_ relaciones que se han_1179 printer.shtml].

Jiménez de la Espada, Marcos. 1965. Relaciones geográficas de Indias, Madrid: Atlas. 
Kabatek, Johannes. 2005. “Tradiciones discursivas y cambio lingüístico”. Lexis, XXIX 2: 151177.

2013. “Es posible una lingüística histórica basada en un corpus representativo?” Iberoromania: Revista dedicada a las lenguas y literaturas iberorrománicas de Europa y América 77, 8-28.

Lope Blanch, Juan M. 1994. "Perspectivas de la investigación sobre el español de América". Actas do XIX Congreso Internacional de Lingüistica e Filoloxía Románicas: 861-868.

Lüdtke, Jens, 2014. Los orígenes de la lengua española en América. Los primeros cambios en las Islas Canarias, las Antillas y Castilla del Oro. Madrid: Iberoamericana.

Mignolo, Walter D. 1982. "Cartas, crónicas y relaciones del descubrimiento y la conquista". Historia de la literatura hispanoamericana, tomo I. Época colonial. Madrid: Ediciones Cátedra: 57-110.

1987. "El mandato y la ofrenda: la descripción de la ciudad y provincia de Tlaxcala, de Diego Muñoz Camargo y las Relaciones de Indias". Nueva Revista de Filología Hispánica 35/2: 451-484.

Moreno de Alba, José G. 1992. Diferencias léxicas entre España y América. Madrid: Mapfre.

Oesterreicher, Wulf. 2004. "Textos entre inmediatez y distancia comunicativas: el problema de lo hablado escrito en el Siglo de Oro". Historia de la lengua española, Barcelona: Ariel: 729-770.

Parodi, Claudia. 2008. "Lingüística de corpus: una introducción al ámbito". Revista de Lingüistica Teórica y Aplicada, 46: 93-119.

Patiño, Víctor. 1983. Relaciones Geográficas de la Nueva Granada (siglos XVI a XIX), Cali: Cespedesia.

Quirós García, M. y J. L. Ramírez Luengo 2015. “Observaciones sobre el léxico del español de Yucatán (1650-1800)”. Revista de Filología Española XCV: 183-210.

Rivarola, José L. 2001: El español de América en su historia, Valladolid: Universidad de Valladolid.

Rona, José P. 1969. “¿Qué es un Americanismo?”. Actas del Simposio de México: Actas, Informes y Comunicaciones. México: UNAM: 135-148.

Sala, Marius, Dan Munteanu, Valeria Neagu y Tudora Sandru Olteanu, 1982. El español de América, Bogotá: Instituto Caro y Cuervo.

Sánchez Méndez, Juan P. 2012. "Lo oral y lo escrito en los textos coloniales hispanoamericanos". En pos de la palabra viva: huella de la oralidad en textos antiguos. Estudios en honor al profesor Rolf Eberenz, Bern: Peter Lang: 75-95.

Solano, Francisco. 1988. Cuestionario para la formación de las Relaciones Geográficas. Siglos XVI /XIX. Madrid: CSIC, XVII-XXVII.

Stoll, Eva. 1998. "Géneros en la historiografía indiana: modelos y transformaciones". Competencia escrita, tradiciones discursivas y variedades lingüisticas. Aspectos del español europeo y americano en los siglos XVI y XVII, Frankfurt/Madrid: Vervuert/Iberoamericana: $143-168$.

Torres Torres, Antonio. 2004. Procesos de americanización del léxico hispánico. Valencia: Universidad.

Valcárcel Martínez. Simón. 1997. Las Crónicas de Indias como expresión y configuración de la mentalidad renacentista. Granada: Diputación.

Wesch, Andreas. 1998. "Hacia una tipología lingüística de textos administrativos y jurídicos españoles (siglos XV-XVII)". Competencia escrita, tradiciones discursivas y variedades lingüisticas. Aspectos del español europeo y americano en los siglos XVI y XVII, Frankfurt/Madrid: Vervuert/Iberoamericana: 186-215.

Zamora Munné, Juan Clemente. 1976. Indigenismos en la lengua de los conquistadores. Uprex. 